\title{
Visible light photocatalytic degradation of microplastic residues with zinc oxide nanorods
}

\author{
Tajkia Syeed Tofa ${ }^{1,4} \cdot K_{\text {Karthik Laxman Kunjali }}^{2} \cdot$ Swaraj Paul $\left.\right|^{3} \cdot J^{\prime}$ Lydeep Dutta ${ }^{2}$
}

Received: 27 December 2018 / Accepted: 19 January 2019 / Published online: 16 February 2019

(c) The Author(s) 2019

\begin{abstract}
Microplastics have recently become a major environmental issue due to their ubiquitous distribution, uncontrolled environmental occurrences, small sizes and long lifetimes. Actual remediation methods include filtration, incineration and advanced oxidation processes such as ozonation, but those methods require high energy or generate unwanted by-products. Here we tested the degradation of fragmented, low-density polyethylene (LDPE) microplastic residues, by visible light-induced heterogeneous photocatalysis activated by zinc oxide nanorods. The reaction was monitored using Fourier-transform infrared spectroscopy, dynamic mechanical analyser and optical imaging. Results show a 30\% increase of the carbonyl index of residues, and an increase of brittleness accompanied by a large number of wrinkles, cracks and cavities on the surface. The degree of oxidation was directly proportional to the catalyst surface area. A mechanism for polyethylene degradation is proposed.
\end{abstract}

Keywords Microplastic $\cdot$ Low-density polyethylene $\cdot$ Photocatalysis $\cdot$ Zinc oxide $\cdot$ Nanotechnology $\cdot$ Visible light

\section{Introduction}

Recent studies have shown the ubiquitous distribution of fragmented plastics of sizes less than $5 \mathrm{~mm}$, typically referred to as microplastics, in the biosphere, due to years of improper disposal of plastic materials, mismanagement and negligent littering (Eerkes-Medrano et al. 2015, Van Cauwenberghe et al. 2015, Auta et al. 2017). A small fraction

Electronic supplementary material The online version of this article (https://doi.org/10.1007/s10311-019-00859-z) contains supplementary material, which is available to authorized users.

Joydeep Dutta

joydeep@kth.se

1 School of Architecture and the Built Environment, Department of Sustainable Development, Environmental Science and Engineering, KTH Royal Institute of Technology, Stockholm, Sweden

2 Functional Materials, Department of Applied Physics, School of Engineering Sciences, KTH Royal Institute of Technology, Isafjordsgatan 22, Kista, 16440 Stockholm, Sweden

3 PP Polymer AB, Krossgatan 15, Vällingby, 16250 Stockholm, Sweden

4 Department of Civil and Environmental Engineering (CEE), Islamic University of Technology (IUT), Gazipur, Bangladesh of larger sized plastic materials are recovered, incinerated or recycled for further use. The rest of the plastics end up in landfills, waterways, drainage systems and wastewater plants. Wastewater treatment plants have been identified as one of the major potential sources of microplastics pollution in aquatic systems mainly contributed by consumer plastics, industrial abrasion, air blasting media, cosmetic products, textiles, medicines as well as the breakdown of larger particles (Bergmann et al. 2015; Talvitie et al. 2015). Several studies have suggested advanced treatment technologies for the removal of microplastics from wastewater treatment system (Talvitie et al. 2017). Research is also focusing on the development of sustainable, bio-based plastic polymers (Kuswandi 2017; Brandelli et al. 2017).

Existing approaches for handling waste plastic materials are thermal, catalytic, mechanical, chemical, ozonation and photo-oxidative degradation (Klein et al. 2018); yet studies showed that photocatalysis could be viable, inexpensive and energy efficient for polymer degradation. Photocatalysis is a light-mediated redox process, wherein nanostructured semiconductors excited with appropriate light energy lead to the creation of exciton pairs, which react with surrounding water/moisture to produce highly reactive species like superoxides and hydroxyl radicals that can effectively oxidize organic species including polymers (Ali et al. 2016; Qi et al. 2017; Çolak et al. 2017; Baruah et al. 2016). 
Amongst popular metal oxide photocatalysts, $\mathrm{ZnO}$ stands out to be the most promising owing to its band gap $(3.37 \mathrm{eV})$, excellent optical properties, high redox potential, better electron mobility and non-toxicity. In addition, $\mathrm{ZnO}$ is easy to synthesize and can be formed into different shapes and sizes using facile low-temperature hydrothermal growth processes (Qi et al. 2017; Baruah and Dutta 2009; Çolak et al. 2017). 'Nano' sized materials are of great importance due to high surface to volume ratio compared to bulk materials as photocatalysis is a surfacedriven phenomenon (Baruah et al. 2016).

In this study, $\mathrm{ZnO}$ nanorod photocatalysts were used to degrade LDPE film (residual), which is an abundant microplastic pollutant in wastewater systems (Talvitie et al. 2017). Suitability of photocatalysis as a process to degrade solid phase LDPE residues in water was evaluated and a possible chemical pathway has been proposed.

\section{Materials and methods}

\section{Reagents}

Zinc acetate dihydrate $\left[\mathrm{Zn}\left(\mathrm{CH}_{3} \mathrm{COO}\right)_{2}\right.$, molecular weight: $219.5 \mathrm{~g} / \mathrm{mol}]$, Zinc nitrate hexahydrate $\left[\mathrm{Zn}\left(\mathrm{NO}_{3}\right)_{2} \cdot 6 \mathrm{H}_{2} \mathrm{O}\right.$, molecular weight: $297.47 \mathrm{~g} / \mathrm{mol}]$ and Hexamethylenetetramine $\left[\mathrm{C}_{6} \mathrm{H}_{12} \mathrm{~N}_{4}\right.$, molecular weight: $\left.140.19 \mathrm{~g} / \mathrm{mol}\right]$ were purchased from Sigma-Aldrich. Commercially available, solid LDPE film of $50 \mu \mathrm{m}$ thicknesses was used for the degradation studies.

\section{Growth of zinc oxide nanorods}

Zinc oxide $(\mathrm{ZnO})$ nanorods were hydrothermally grown on glass substrates (Baruah and Dutta 2009). Briefly, a seed $\mathrm{ZnO}$ layer was formed by spray pyrolysis of $10 \mathrm{mM}$ $\mathrm{Zn}\left(\mathrm{CH}_{3} \mathrm{COO}\right)_{2}$ at $1 \mathrm{~mL} / \mathrm{min}$ on clean microscopic glass slides placed on a hot plate at $350{ }^{\circ} \mathrm{C}$. $\mathrm{ZnO}$ nanorods were grown by subsequently placing the seeded substrates in a chemical bath of equimolar solutions of hexamine and zinc nitrate hexahydrate in DI water for $5 \mathrm{~h}$ at $90{ }^{\circ} \mathrm{C}$, followed by post-synthesis annealing in air at $350^{\circ} \mathrm{C}$ for $1 \mathrm{~h}$.

\section{Experimental set-up for photocatalytic degradation of low-density polyethylene film}

Photocatalytic degradation of low-density polyethylene (LDPE) film of size $(1 \mathrm{~cm} \times 1 \mathrm{~cm})$ was carried out for $175 \mathrm{~h}$ in a petri dish containing the photocatalyst and deionized water. A $50 \mathrm{~W}$ dichroic halogen lamp in ambient air was used for visible light illumination $(\approx 60-70$ klux $)$ from a distance of $10 \mathrm{~cm}$ (supporting info. Fig. S1).

\section{Characterization techniques}

Scanning electron microscope (SEM) (ZEISS Ultra 55) was used for the determination of surface morphology and size ranges of catalysts. A digital microscope (Leica: DFC295) fitted with a 3.0 megapixel camera was used for observing the morphological changes over the surface of the exposed LDPE film.

Dynamic mechanical analyser (DMA) was used to determine mechanical changes within the polymer at molecular levels. Both controlled, and pre-stressed LDPE films were exposed to a sinusoidal stress and strain at different temperatures $\left(-20^{\circ} \mathrm{C}\right.$ to $\left.+100^{\circ} \mathrm{C}\right)$ at $1 \mathrm{~Hz}$ frequency. Storage modulus $\left(E_{\mathrm{s}}\right)$ that represents the elastic behaviour of polymer was calculated as in Eq. (1).

Storage modulus,

$E_{s}=\sigma / \in * \cos \beta$

where $\sigma=$ maximum stress, $\epsilon=$ maximum strain and $\beta=$ phase angle in radian between the dynamic stress and the dynamic strain in a visco-elastic material subjected to a sinusoidal oscillation.

Fourier-transform infrared (FTIR) spectroscopy (Nicolet is 10: Thermo scientific) was used for the qualitative observation of molecular changes of the functional groups. The effect of photocatalytic oxidation was monitored by determining both carbonyl and vinyl indices; carbonyl index being the ratio of areas under the absorbance peaks at $1712 \mathrm{~cm}^{-1}$ and $1372 \mathrm{~cm}^{-1}$; vinyl index being the ratio of the area under the absorbance of vinyl group at $909 \mathrm{~cm}^{-1}$ to the area under the same reference peak (Ali et al. 2016).

\section{Result and discussion}

\section{Morphological variations of photodegraded low-density polyethylene films}

Cracks and spots on the low-density polyethylene (LDPE) film where the photo-mediated oxidation process was prevalent after $175 \mathrm{~h}$ of exposure can be visually observed from optical images shown in Fig. 1. Chromophoric groups, manufacturing defects and weak links act as initiation sites for the oxidation process, in turn leading to degradation of the molecular bonds upon prolonged photocatalytic exposure (Yousif and Haddad 2013). Few cracks observed on the control LDPE film might be introduced from manufacturing processes. 
Fig. 1 Microscopic images of $\mathbf{i}$ as received low-density polyethylene (LDPE) and photo-irradiated LDPE for $175 \mathrm{~h}$ in contact with nanorods ii $\mathrm{ZnO}$ (3 $\left.\mathrm{mM} \_5 \mathrm{~h}\right)$ iii $\mathrm{ZnO}$ (10 mM_5 h), iv $\mathrm{ZnO}$ (20 mM_5 h) exhibiting the development of cracks, holes and spots
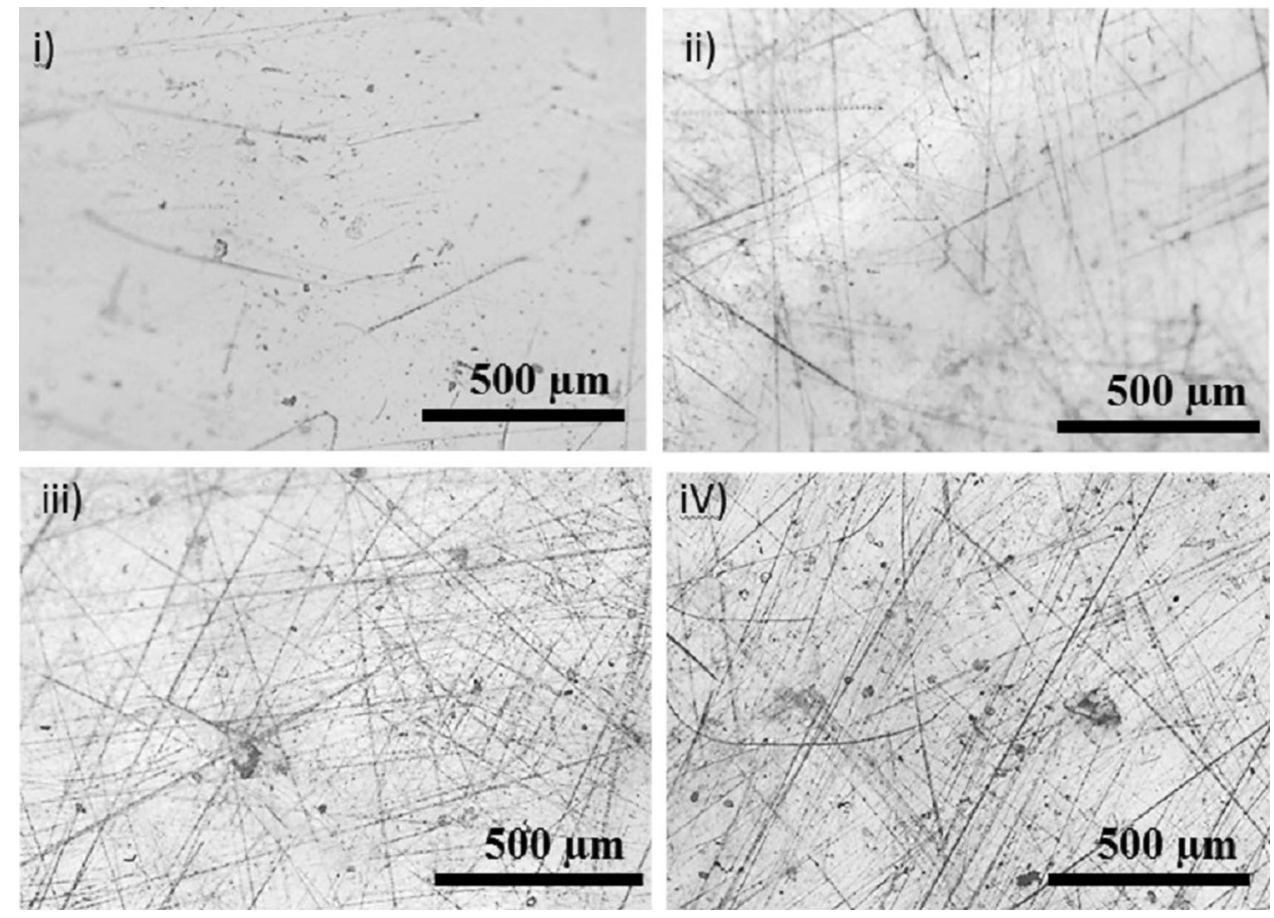

It is generally agreed that excitation of the photocatalyst under optimum light energy leads to the formation of hydroxyl radicals, which have a high oxidation capacity for degrading organic pollutants. Hence longer rods, which by virtue of their increased surface area can generate higher number of radicals, lead to a higher degradation of the LDPE film surface. Further evidence of the LDPE oxidation is also provided by DMA analysis.

\section{Surface topography and composition of designed catalysts}

Scanning electron microscopy (SEM) micrographs show that the $\mathrm{ZnO}$ nanorods were 250 to $1750 \mathrm{~nm}$ long varying in width from 34 to $65 \mathrm{~nm}$ for the precursor concentrations of $3 \mathrm{mM}, 5 \mathrm{mM}, 10 \mathrm{mM}$ and $20 \mathrm{mM}$, leading to increment of total effective surface area to $6.5,22,49$ and $55 \mathrm{~cm}^{2}$, respectively (supporting info. Fig. S2 and Table S1). This suggests that longer rods have higher effective surface area and could be more effective for microplastics degradation.

\section{Changes in visco-elastic properties of photocatalysed low-density polyethylene films}

Dynamic mechanical analyser (DMA) analyses the storage modulus $\left(E_{\mathrm{s}}\right)$ as a function of temperature, where $E_{\mathrm{s}}$ represents the energy stored with increasing temperature per cycle of sinusoidal deformation, which in turn represents the changes in the visco-elastic properties of the LDPE films. As shown in Fig. 2, temperature-dependent

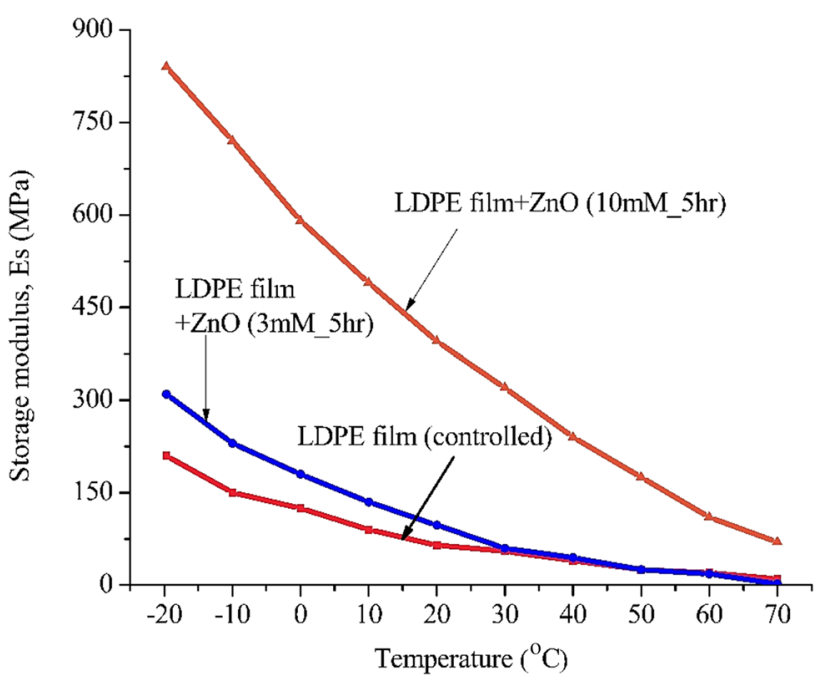

Fig. 2 Variation in the elastic properties of low-density polyethylene films upon photo-irradiation in the presence of zinc oxide $(\mathrm{ZnO})$ (3 mM_5 h), ZnO (10 mM_5 h) catalysts. It can be noted that higher value of storage modulus $\left(E_{\mathrm{s}}\right)$ reveals the alteration to more stiffer and tougher elastic properties due to photocatalysis in comparison with non-irradiated (control) film

variations of the storage modulus for the films irradiated in the presence of photocatalysts showed a marked increase in $E_{\mathrm{S}}$, indicating increased stiffness. The degree of stiffness for same level of photo-irradiation was observed to be a function of the rod length, again indicating to the hypothesis that higher surface area leads to a more effective photocatalytic performance. In fact, $E_{\mathrm{s}}$ values for the 

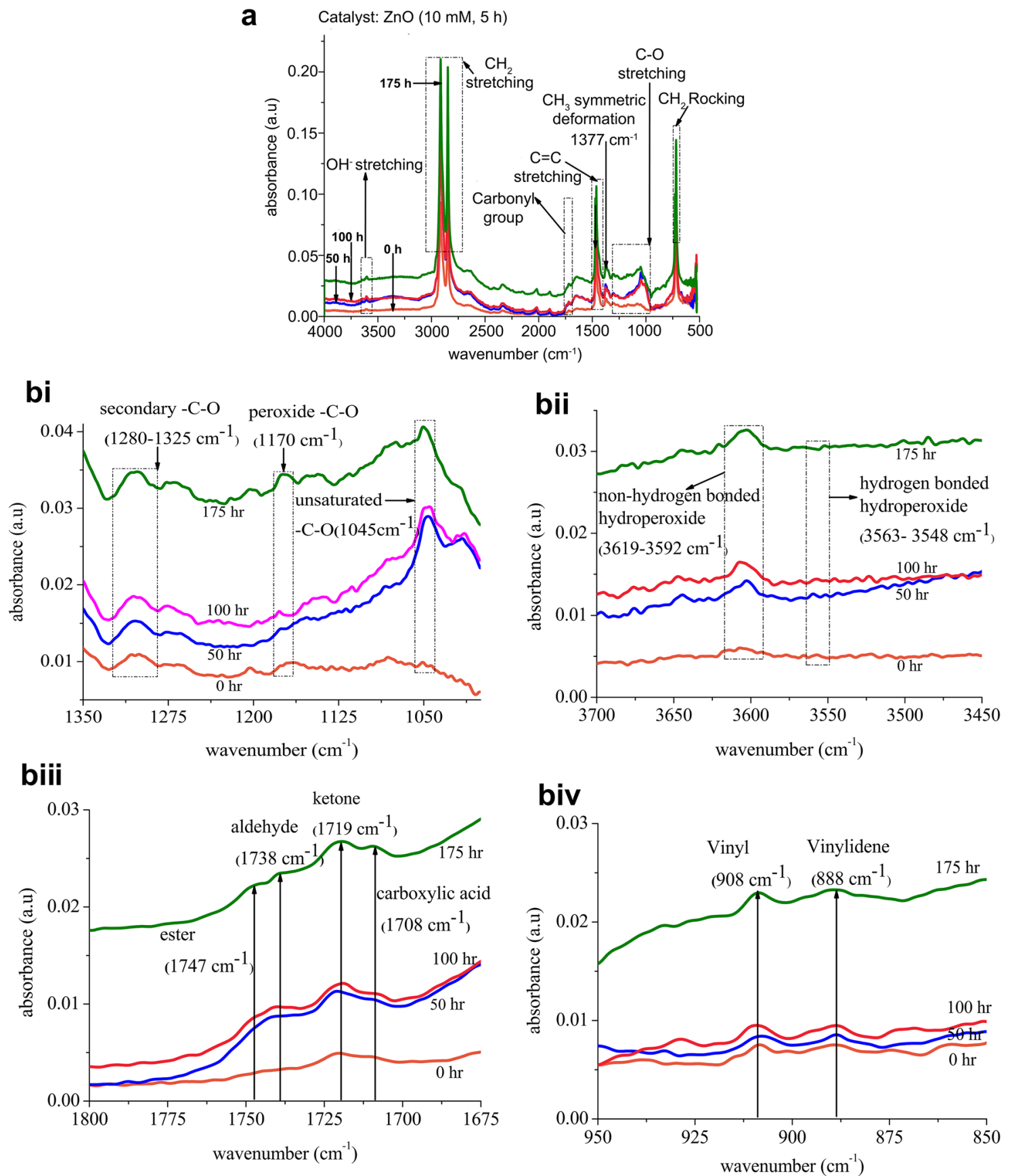

Fig. 3 a FTIR spectra of low-density polyethylene film over $175 \mathrm{~h}$ of visible light photocatalysis in the presence of $\mathrm{ZnO}$ (10 mM $5 \mathrm{~h}$ ) nanorods. b Evolution of different functional groups $\mathbf{i}$ peroxides, ii hydroperoxides, iii carbonyl and iv unsaturated groups during photocatalysis process

$20 \mathrm{mM} \mathrm{ZnO}$ photocatalyst sample could not be extracted as the sample ruptured due to non-sustenance of the prestress while performing the measurements. Hence, it gives a clear indication that the irradiated films lose their elasticity due to chain scission within the polymeric matrix, as a result of photocatalytic oxidation (Sebaa et al. 1993; Briassoulis 2005).

\section{Temporal changes of chemical properties during photocatalysis of low-density polyethylene films}

To better understand the LDPE degradation phenomenon, the samples were characterized using time-dependent FTIR spectroscopy as shown in Fig. 3. Baselines were extracted 
from the control (non-irradiated) LDPE with characteristic vibrational peaks at $710 \mathrm{~cm}^{-1}$, and $719 \mathrm{~cm}^{-1}$ (rocking deformation of $-\mathrm{CH}_{2}$ ), $2847 \mathrm{~cm}^{-1}, 2915 \mathrm{~cm}^{-1}$ (symmetric and asymmetric $-\mathrm{CH}_{2}$ stretch), $1462 \mathrm{~cm}^{-1}, 1472 \mathrm{~cm}^{-1}$ $\left(-\mathrm{C}=\mathrm{C}-\right.$ stretch), and $1377 \mathrm{~cm}^{-1}$ (weak symmetric deformation of $-\mathrm{CH}_{3}$ group) (Gulmine et al. 2002; Ali et al. 2016; Socrates 2004). Chemical transformation during the photodegradation resulted in the formation of new functional groups like carbonyl, hydroperoxide, peroxides and unsaturated groups within the bands from $1700-1760 \mathrm{~cm}^{-1}$, $3600-3610 \mathrm{~cm}^{-1}, 1100-1300 \mathrm{~cm}^{-1}$ and $880-920 \mathrm{~cm}^{-1}$, respectively, which is in agreement with previous studies (Gardette et al. 2013; Luongo 1960; Qin et al. 2003).

A closer observation of the vibrational bands (Fig. 3b) leads to a better understanding of the degradation mechanism. The formation of bonded and non-hydrogen-bonded alcohol species was confirmed by the stretching peaks at $3553 \mathrm{~cm}^{-1}$ and $3606 \mathrm{~cm}^{-1}$. Primary $\left(1170 \mathrm{~cm}^{-1}\right)$, secondary $\left(1280-1325 \mathrm{~cm}^{-1}\right)$ and double-bonded $\left(1048 \mathrm{~cm}^{-1}\right)$ peroxide groups were also observed. Fairly broad and clear peaks observed at $1708 \mathrm{~cm}^{-1}, 1719 \mathrm{~cm}^{-1}, 1738 \mathrm{~cm}^{-1}$ and $1747 \mathrm{~cm}^{-1}$ that can be assigned to carboxylic acid, ketones, aldehyde and esters belonging to carbonyl groups (Kumanayaka 2010; Socrates 2004). It has been previously suggested that photo-oxidation of ketones results in the formation of unsaturated vinylidene and vinyl groups at $888 \mathrm{~cm}^{-1}$ and $909 \mathrm{~cm}^{-1}$, respectively (Gardette et al. 2013). Interestingly, vinylidene groups seem to form rapidly before decaying and vinyl groups increase simultaneously with the generation of ketones, due to Norrish type II reactions, which is a part of the photocatalytic degradation process.

\section{Photocatalytic degradation indices}

The evolution of carbonyl and vinyl groups are the main indicators for monitoring the degree of degradation of a polymer. Table 1 shows the carbonyl and vinyl indices of the LDPE films after photocatalysis with different catalysts, wherein a $30 \%$ increase in the $\mathrm{CI}$ and VI indexes for longer

Table 1 Carbonyl index (CI) and vinyl index (VI) of low-density polyethylene (LDPE) films after $175 \mathrm{~h}$ exposure to visible light in the presence of different photocatalysts for monitoring the degree of degradation where higher values suggest better oxidation

\begin{tabular}{lllll}
\hline $\begin{array}{l}\text { Param- } \\
\text { eters }\end{array}$ & $\begin{array}{l}\text { Control } \\
\text { (non-irra- } \\
\text { diated) }\end{array}$ & $\begin{array}{l}\text { LDPE+ZnO } \\
\left(3 \mathrm{mM} \_5 \mathrm{~h}\right)\end{array}$ & $\begin{array}{l}\text { LDPE+ZnO } \\
\left(10 \mathrm{mM} \_5 \mathrm{~h}\right)\end{array}$ & $\begin{array}{l}\text { LDPE+ZnO } \\
\left(20 \mathrm{mM} \_5 \mathrm{~h}\right)\end{array}$ \\
\hline CI & 0.71 & 1.17 & 1.38 & 1.51 \\
VI & 0.51 & 0.9 & 1.12 & 1.3 \\
\hline
\end{tabular}

Zinc oxide $(\mathrm{ZnO})$
$\mathrm{ZnO}$ rods clearly demonstrates the photocatalytic improvement with catalyst surface area. Initial carbonyl and vinyl values of 0.71 and 0.51 indicate the presence of inherent chromophoric groups which are the primary initiators for the degradation (Ali et al. 2016; Yousif and Haddad 2013).

\section{Proposed degradation mechanism}

Based on the results obtained in this study, the following degradation pathway for the LDPE film is proposed. The generated hydroxyl and superoxide radicals from catalyst initiate degradation at weak spots (like chromophoric groups, defects) of the long polymeric chains to generate low molecular weight polyethylene alkyl radicals (Eq. 2), followed by chain breaking, branching, crosslinking and oxidation of LDPE. Subsequently (Eqs. 3-5), peroxy radicals are formed with oxygen incorporation, followed by the abstraction of hydrogen atoms from the polymeric chains to form hydroperoxide groups. The hydroperoxide groups are the foremost oxygenated products that regulate the rate of photocatalytic degradation, wherein their dissociation into alkoxy radicals undergoes successive reactions to generate carbonyl and vinyl group containing species (Eqs. 7-8), which in turn lead to chain cleavage. Hence the presence of carbonyl and vinyl groups confirms the photo-oxidative degradation of LDPE films in the presence of catalysts that terminates by generating volatile organic compounds like ethane and formaldehyde. However, further oxidation can lead to complete mineralization to produce carbon dioxide and water as explained below (Hartley and Guillet 1968; Shang et al. 2003; Liang et al. 2013).

$$
\left(-\mathrm{CH}_{2}-\mathrm{CH}_{2}-\right)_{\mathrm{n}}+{ }^{*} \mathrm{OH}^{-} \rightarrow\left(-\mathrm{CH}_{2}-{ }^{*} \mathrm{CH}-\right)_{\mathrm{n}}+\mathrm{H}_{2} \mathrm{O}
$$

$\left(-\mathrm{CH}_{2}-{ }^{*} \mathrm{CH}-\right)_{\mathrm{n}}+\mathrm{O}_{2} \rightarrow\left(-\mathrm{CH}_{2}-\mathrm{HCOO}^{*}-\mathrm{CH}_{2}-\right)_{\mathrm{n}}$

$$
\begin{aligned}
& \left(-\mathrm{CH}_{2}-\mathrm{HCOO}^{*}-\mathrm{CH}_{2}-\right)_{\mathrm{n}}+\left(-\mathrm{CH}_{2}-\mathrm{CH}_{2}-\right)_{\mathrm{n}} \\
& \quad \rightarrow\left(-\mathrm{CH}_{2}-\mathrm{HCOOH}-\mathrm{CH}_{2}-\right)+\left(-\mathrm{CH}_{2}-{ }^{*} \mathrm{CH}\right)_{n}
\end{aligned}
$$

$\left(-\mathrm{CH}_{2}-\mathrm{HCOOH}-\mathrm{CH}_{2}-\right)_{\mathrm{n}} \rightarrow\left(-\mathrm{CH}_{2}-\mathrm{HCO}^{*}-\mathrm{CH}_{2}-\right)_{n}+{ }^{*} \mathrm{OH}^{-}$

$\left(-\mathrm{CH}_{2}-\mathrm{HCO}^{*}-\mathrm{CH}_{2}-\right)_{\mathrm{n}} \rightarrow$ Carbonyl groups

Norrish type I

$\left(-\mathrm{CH}_{2}-\mathrm{CO}-\mathrm{CH}_{2}-\right)_{\mathrm{n}} \rightarrow\left(-\mathrm{CH}_{2}-\mathrm{CO}^{*}\right)_{\mathrm{n}}+\left({ }^{*} \mathrm{CH}_{2}-\mathrm{CH}_{2}\right)_{n}$

Norrish type II

$\left(-\mathrm{CH}_{2}-\mathrm{CO}-\mathrm{CH}_{2}-\right)_{\mathrm{n}} \rightarrow\left(-\mathrm{CH}_{2}-\mathrm{CO}\right)_{\mathrm{n}}+\left({ }^{*} \mathrm{CH}_{2}=\mathrm{CH}\right)_{\mathrm{n}}$ 


$$
\begin{aligned}
& \left(-\mathrm{CH}_{2}-\mathrm{HCO}\right)+\left(-\mathrm{CH}_{2}-\mathrm{COOH}\right) \\
& \quad+\left(-\mathrm{CH}_{2}-\mathrm{CO}-\mathrm{CH}_{2}-\right) \rightarrow \mathrm{CO}_{2}+\mathrm{H}_{2} \mathrm{O}
\end{aligned}
$$

\section{Conclusion}

This study successfully demonstrates the degradation of microplastic fragments, low-density polyethylene film (LDPE) in water using visible light excited heterogeneous $\mathrm{ZnO}$ photocatalysts. Photocatalytic LDPE oxidation led to formation of low molecular weight compounds like hydroperoxides, peroxides, carbonyl and unsaturated groups, resulting in increased brittleness along with wrinkles, cracks and cavities on the LDPE surface. Furthermore, catalyst surface area was found to be important towards enhancing the LDPE degradation. The results provide new insights into the use of a clean technology for addressing the global microplastic pollution with reduced by-products.

Acknowledgements This article was supported by the CLAIM (Cleaning Litter by developing and Applying Innovative Methods in European Seas) project which receives funding from the European Union's Horizon 2020 research and innovation programme under Grant agreement No 774586. The authors would also like to thank PP Polymer AB and Functional Materials (FNM), Department of Applied Physics, KTH, Sweden for support.

Open Access This article is distributed under the terms of the Creative Commons Attribution 4.0 International License (http://creativeco mmons.org/licenses/by/4.0/), which permits unrestricted use, distribution, and reproduction in any medium, provided you give appropriate credit to the original author(s) and the source, provide a link to the Creative Commons license, and indicate if changes were made.

\section{References}

Ali SS, Qazi IA, Arshad M et al (2016) Photocatalytic degradation of low density polyethylene (LDPE) films using titania nanotubes. Environ Nanotechnol Monit Manag 5:44-53. https://doi. org/10.1016/j.enmm.2016.01.001

Auta HS, Emenike CU, Fauziah SH (2017) Distribution and importance of microplastics in the marine environment: a review of the sources, fate, effects, and potential solutions. Environ Int 102:65176. https://doi.org/10.1016/j.envint.2017.02.013

Baruah S, Dutta J (2009) Hydrothermal growth of $\mathrm{ZnO}$ nanostructures. Sci Technol Adv Mater 10:013001. https://doi.org/10.1088/14686996/10/1/013001

Baruah S, Najam Khan M, Dutta J (2016) Perspectives and applications of nanotechnology in water treatment. Environ Chem Lett 14:1-14. https://doi.org/10.1007/s10311-015-0542-2

Bergmann M, Gutow L, Klages M (2015) Marine anthropogenic litter. Springer, Cham

Brandelli A, Brum LFW, dos Santos JHZ (2017) Nanostructured bioactive compounds for ecological food packaging. Environ Chem Lett 15:193. https://doi.org/10.1007/s10311-017-0621-7

Briassoulis D (2005) The effects of tensile stress and the agrochemical Vapam on the ageing of low density polyethylene (LDPE) agricultural films. Part I. Mechanical behaviour. Polym Degrad Stab 88:489-503. https://doi.org/10.1016/j.polymdegradstab.2004.11.021
Çolak H, Karaköse E, Duman F (2017) High optoelectronic and antimicrobial performances of green synthesized $\mathrm{ZnO}$ nanoparticles using Aesculus hippocastanum. Environ Chem Lett 15:547-552. https://doi.org/10.1007/s10311-017-0629-z

Eerkes-Medrano D, Thompson RC, Aldridge DC (2015) Microplastics in freshwater systems: a review of the emerging threats, identification of knowledge gaps and prioritisation of research needs. Water Res 75:63-82. https://doi.org/10.1016/j.watres.2015.02.012

Gardette M, Perthue A, Gardette JL et al (2013) Photo- and thermaloxidation of polyethylene: comparison of mechanisms and influence of unsaturation content. Polym Degrad Stab 98:2383-2390. https://doi.org/10.1016/j.polymdegradstab.2013.07.017

Gulmine JV, Janissek PR, Heise HM et al (2002) Polyethylene characterization by FTIR. Polym Test 21:557-563. https://doi. org/10.1016/S0142-9418(01)00124-6

Hartley GH, Guillet JE (1968) Photochemistry of ketone polymers. I. Studies of Ethylene-carbon monoxide copolymers. J Am Chem Soc 1:165-170. https://doi.org/10.1021/ma60002a012

Klein S, Dimzon IK, Eubeler J et al (2018) Analysis, occurrence, and degradation of microplastics in the aqueous environment. In: Wagner M, S L (eds) Freshwater microplastics. The handbook of environmental chemistry. Springer, Cham

Kumanayaka TO (2010) Photo-oxidation and biodegradation of polyethylene nanocomposites. Dessertation, RMIT University

Kuswandi B (2017) Environmental friendly food nano-packaging. Environ Chem Lett 15:205. https://doi.org/10.1007/s10311-017-0613-7

Liang W, Luo Y, Song S et al (2013) High photocatalytic degradation activity of polyethylene containing polyacrylamide grafted $\mathrm{TiO}_{2}$. Polym Degrad Stab 98:1754-1761. https://doi.org/10.1016/j. polymdegradstab.2013.05.027

Luongo JP (1960) Infrared study of oxygenated groups formed in polyethylene during oxidation. J Polym Sci 42:139-150. https://doi. org/10.1002/pol.1960.1204213916

Qi K, Cheng B, Yu J et al (2017) Review on the improvement of the photocatalytic and antibacterial activities of $\mathrm{ZnO}$. J Alloys Compd 727:792-820. https://doi.org/10.1016/j.jallcom.2017.08.142

Qin H, Zhao C, Zhang S et al (2003) Photo-oxidative degradation of polyethylene/montmorillonite nanocomposite. Polym Degrad Stab 81:497-500. https://doi.org/10.1016/S0141-3910(03)00136-8

Sebaa M, Servens C, Pouyet J (1993) Natural and artificial weathering of low-density polyethylene (LDPE): calorimetric analysis. J App Polym Sci 47:1897-1903. https://doi.org/10.1002/app.1993.070471101

Shang J, Chai M, Zhu Y (2003) Photocatalytic degradation of polystyrene plastic under fluorescent light. J Am Chem Soc 37:44944499. https://doi.org/10.1021/es0209464

Socrates G (2004) Infrared and Raman characteristic group frequencies: tables and charts, 3rd ed. Wiley, New York

Talvitie J, Heinonen M, Pääkkönen JP et al (2015) Do wastewater treatment plants act as a potential point source of microplastics? Preliminary study in the coastal Gulf of Finland, Baltic Sea. Water Sci Technol 72:1495-1504. https://doi.org/10.2166/wst.2015.360

Talvitie J, Mikola A, Koistinen A et al (2017) Solutions to microplastic pollution - removal of microplastics from wastewater effluent with advanced wastewater treatment technologies. Water Res 123:401407. https://doi.org/10.1016/j.watres.2017.07.005

Van Cauwenberghe L, Devriese L, Galgani F, Robbens J, Janssen CR (2015) Microplastics in sediments: a review of techniques, occurrence and effects. Marine Environ Res 111:5-17. https:// doi.org/10.1016/j.marenvres.2015.06.007

Yousif E, Haddad R (2013) Photodegradation and photostabilization of polymers, especially polystyrene: review. SpringerPlus 2:398. https://doi.org/10.1186/2193-1801-2-398

Publisher's Note Springer Nature remains neutral with regard to jurisdictional claims in published maps and institutional affiliations. 